\title{
Shanghai international curriculum of college teachers' overseas training project - Take training courses in the University of Alberta in Canada in 2013 for example
}

\author{
Yan WANG \\ School of Medical Instrument and Food Engineering \\ University of Shanghai for Science and Technology \\ Shanghai, China
}

\section{Li SUI}

School of Medical Instrument and Food Engineering University of Shanghai for Science and Technology

Shanghai, China

\author{
Dingdong SUN \\ School of Business \\ East China University Of Science And Technology \\ Shanghai, China
}

\begin{abstract}
Lihua JU
School of Medical Instrument and Food Engineering University of Shanghai for Science and Technology

Shanghai, China
\end{abstract}

\begin{abstract}
In order to carry out and implement Ministry of Education's "Study in China Program", the Shanghai Education Commission established Shanghai international curriculum of college teachers' overseas training project in 2010, I had the honor to participate in the project in 2013 and went to the training courses in University of Alberta in Canada for three months. "Student-centered, and promote active learning" is the theme of this training. No matter from English learning (including oral and written), teaching (including teaching mode, select and design learning activities, classroom observation and micro-teaching, second language teaching, motivate and participation, etc.), or from the learning of Instructional Technology (such as the use of multimedia software and hardware technology), I reaped no little benefit. A variety of teaching methods and advanced course management systems and online teaching platform, making the effectiveness of the training courses became doubled but we also saw some shortcomings and areas for improvement from this training course. These are enough to give us reasons to believe that through constant practice and improvement, the Ministry of Education's project of "Studying in China Program" will rapidly promoted and implemented successfully.
\end{abstract}

Keywords- "Studying in China Program", Shanghai international curriculum of college teachers'overseas training project, University of Alberta, training courses

\section{INTRODUCTION}

In September 2010, the "National medium and long term Education Reform and Development Plan (2010-2020)" was promulgated then Shanghai Municipal Education Commission issued "Shanghai medium and long term Education Reform and Development Plan (2010-2020)", clearly pointed out educational internationalization to enable students to have the ability of international exchange, international understanding, international cooperation and competitiveness. Education Plan also noted "further expands the scale of foreign students, implements Study in China Program." To better carry out and implement the spirit of the education program, and to adapt the new situation at home and abroad, in the meeting of the national working conference about study in China in September 28, 2010, the Ministry of Education announced the "Study in China Program." The program established the development strategic target in the next decade, making China to become Asia's largest destination for study abroad by 2020 , the number of students who study in China will reach 50 million people, students who receive academic education will reach 15 million people.

In order to implement the Ministry of Education's "Study in China Program" to optimize the structure of foreign students, to develop new models and new ways for overseas students, to encourage college students to establish professional curriculum, and encourage colleges and universities to offer degree programs taught in English, in order to attract more high-quality foreign students to further their study in China, Shanghai Municipal Education Commission established Shanghai international curriculum of college teachers' overseas training project in 2010 (hereinafter referred to as "International Training Project"), to afford more teachers to be trained for English teaching in China. From 2010, "International Training Project" sends a group of university teachers abroad each year to attend international teacher training courses. As for the selection of foreign schools, the University of Alberta and the University of Queensland are world's top one hundred schools, admit a large number of international students each year, and have a wealth of international experience in language training; study period are about three or four months; The selected teachers are recommended by Shanghai colleges and they are outstanding young universities' teachers, at least a master's degree or more, and most already have abroad experience or bilingual teaching experience. 


\section{THE INTRODUCTION ABOUT "INTERNATIONAL Training PROJECT" IN University of AlbERTA, CANADA,}

Take the University of Alberta in Canada as an example, for the reason that author visited before, the University of Alberta (UA) is located in the capital city of Alberta Ed Mans Dayton, and has 105 years of history so far, the world's top one hundred. University of Alberta, "International Training Project", also known as English Language Program, ELP established in 1973, designed for higher education whose mother language is not English but need to teach in English. The course not only learns words and sentences, but also provides an opportunity to know another culture and to improve communication skills. The project was undertaken by a group of experienced excellent teachers, they used advanced teaching methods, teaching resources and teaching skills. In 2013, "International Training Project" sent a total of 19 university teachers to Canada as students, studied for 3 months (From 2013-08-12 to 2013-11-08). Course objective is to enable students not only to improve the ability to speak and write English, but also to provide the latest methods of teaching English. So that students become accustomed to study slogan and pattern under English learning environment, and ultimately students will be proficient in English teaching. Courses were taught by different teachers and rich in content, including: 52 hours of English language training; 117 hours study of English teaching (Teaching in English, TIE): Contains curriculum design, classroom control, learning different cultural backgrounds, learning Assessment, the recent developments about learning methods and techniques; and finally there are 10 hours of graduation speech.

Apart from ELP courses, the current "International Training Project" also adds quiz and lectures; students can choose to attend 1-3 door-related courses, study by UA student's side, and each student can experience UA undergraduate or graduate study in their respective areas and benefit a lot.

\section{WORTHY LEARNING EDUCATION EXPERIENCE}

The training content are and benefit from English learning, learning pedagogy and teaching techniques, there is a lot that we can learn from the experience.

\section{A. change the teaching mode, make "solo" into "chorus"}

ELP curriculum contents are rich; teachers are very responsible and full of passion and vitality. They use a variety of active and interesting teaching methods and approaches, try to make each student throw himself into the course. The course theme is clearly, to make "students as teaching center." Classroom activity and it's design enrich the teaching skills and make teaching more lively and effective, the instructional design should strive to make students to fully understand and participate in the teaching process; syllabus revision and improvement; revise on the previous widely used words "master", "familiar" and other words, change them into more specific words" description, write, design." Not only to increase students' understanding of teaching requirements but also to make a reasonable allocation of teaching content. The teaching activities are various, in addition to traditional classroom teaching, there are also impromptu speeches, quizzes, group discussions, written reports and presentations, poster making, teaching practice (Teaching Practice), simulated teaching (such as interviews and making panels) and RPG (role play), etc. In the classroom, purely theoretical teaching takes up a little, students are wished to combine thinking and doing during most of the time, which increases students' enthusiasm and participation. Based on small class teaching, tables and chairs can move freely, according to the lecture content, can be round table panel discussion based, or in semi-group discussions based. Student's seats are also different from time to time according to the packet exchange. In the classroom students should not only listen but also say, think and do. During the whole teaching process, students are the core and teacher focus on instructional design, teaching activities plays the leading role in the whole class, teachers should change "solo" into "students' advocate" to promote active learning. the so-called "active learning" is during bilateral activities, students affected by teachers' education, then give full play to the active and effectively participate in the teaching process, and enhance the consciousness and self-awareness, learn to take the initiative to educate and develop themselves, to become a modern thinking, be self consciousness, to effectively take the initiative to create, to freely carry out social awareness and social practice. Modern pedagogy believe that students are the main body of learning and development, to establish the "student-centered" concept, all teaching activities must mobilize the students' initiative, enthusiasm and creativity as a starting point. However, in the current teaching in our country there are still single-teaching classroom model, which requires the majority of teachers to be actively involved in the teaching reform to take inspiration teaching style and the discussion mode, focus on cultivating students' active learning spirit, teachers in the classroom should change "solo" into "accompaniment", abandon educational concept that can hinder students' practice develop capacity.

\section{B. Use Bloom taxonomy of educational objectives to guide the teaching objectives, clear the role of students}

There is no doubt about the importance of teaching goal, teaching goal means the anticipation of the results of students' study. And teaching goal restricts the teaching process, the methods and the way of classroom activities. According to Bloom taxonomy, teachers need a frame to help them understand and organize the teaching goals, and make it to be clearly understood and implemented. The course, "The selection and design of the teaching activities", during this training teaches us how to design teaching objectives more effectively. We often emphasis too much on textbook content and knowledge when setting teaching objectives, but ignore that the clear teaching objectives should be clear about what students should do, that is to say the objectives should be practical and effective. Bloom Taxonomy teaching objectives based on the complexity of the cognitive processes and continue to strengthen followed by the class: classification memory, understanding, application, analysis, evaluation and creation. Target 
classification has strong operation, and the application is simple and straightforward. Take the course that I learned Mannequin's "Anatomy" curriculum for example, the teaching objectives in the cardiovascular system require for the "Mastering the position and shape of the heart, cardiovascular familiar composition, understanding the composition of the cardiovascular system." In this teaching objective, it didn't make clear how students do can have a clear grasp of knowledge, master and understanding, so that teaching objectives are ambiguous. If take Bloom taxonomy teaching objectives as a guide, teaching objectives can be set to "draw a heart in front view and the rear view of the main structure (including four heart chambers, four ditch, major macro vascular), describe the location of the heart and size." This teaching objective clearly told the students to draw and describe, easier to handle and understand, it is effective in practical situations. Only clarify the role of students can ensure the effective of teaching.

\section{INSUFFICIENT AND RELATIVE RECOMMENDATIONS}

\section{A. Insufficient aspect}

The training programs do still relatively insufficient in relevant professional courses, just sit in professional courses is not enough. Lacking research and teaching exchanges with specialized courses teacher. Maybe appropriately add professional research connected will be better, such as select the relevant professional counterparts teachers to conduct students with research and teaching exchange, arrange correspondingly courses, I believe the effect will be better. To make international teacher training courses better integrated with professional training courses and diagnostic and graft according to the teaching practice of the participants of the project team, it will give greater harvest to each participating student.

\section{B. Suggestions}

The UA's "International Training Project" is very reasonable arrangement in general, the teaching effect is significant, students benefit a lot, but there are some places can be improved. (1) Increase exchanges between each training group. It will bring great convenience for learning and living if people can get advice such as: accommodation, living, shopping, transportation, school facilities, as well as courses and related conditions before departure, it also much more likely to get more revenue in three months. (2) Increase the post-investment training. It will undoubtedly greatly increase the practical benefits of this project if tracks the international curriculum implementation and promotion condition at the end of the project. From a practical look at this project, in terms of course content arrangement, classroom organization, teaching methods, or from the use of hardware and software and student participation, there is still a big gap exists in the teaching effect at home and abroad, there are still a lot to learn and draw.

\section{CONCLUSIONS}

Through this international training courses, students not only have a great improvement in oral and written English, also absorbed the new concept of international education, about how to further improve the teaching skills, teaching mode, teaching practices and have a real practical application feelings, they must adhere to the "student-centered, and promote active learning." Students will be the contributor of the future aboard education if they spread internationalized curriculum into various schools and classrooms. We have reasons to believe that, through constant practice and improvement of the project, the Ministry of Education's "Study in Chinese Program" will be rapidly promoted and implemented successfully.

\section{ACKNOWLEDGEMENTS}

International Teacher Project by Shanghai Municipal Education Commission and the State Scholarship for 1: 1 funded by foreign students in Shanghai I taught college English course construction demonstration, "party ideological and political Moral Higher Education" special funding Shanghai Polytechnic University, and Shanghai University Graduate core Curriculum project funding

\section{References}

[1] "Study in China program," Reading Education and Career, 46-47 (2013).

[2] Ryan, M. Theorizing a model for teaching and assessing reflective learning in higher education. Higher Education Research \& Development32, 244-257 (2013).

[3] Cheng, FQ Reform and Practice for CDIO Engineering Education Model in Curriculum Teaching of Mechanical Design of Higher Vocational Education of China, in Advanced Materials and Information Technology Processing, Pts 1-3, Vol. 271-273. (Ed. JQ Xiong ) 1228-12302011).

[4] Adamo, S. Bilingual Higher Education in the Legal Context:. Group Rights, State Policies and Globalization Common Market Law Review50, 656-659 (2013).

[5] Trahar, S. Globalization and internationalization in higher education:. Theoretical, strategic and management perspectives Compare-a Journal of Comparative and International Education43, 146-148 (2013).

[6] Yelland, R. Globalization's Muse:. Universities and Higher Education Systems in a Changing World Review of Higher Education35, 671672 (2012).

[7] Greenhow, C. \& Belbas, B. Using activity-oriented design methods to study collaborative knowledge-building in e-learning courses within higher education. International Journal of Computer-Supported Collaborative Learning2, 363-391 (2007).

[8] Elsen, CJ Made to stick: Why some ideas survive and others die Library Journal132, 83-83 (2007)..

[9] Tuschhoff, C. Transatlantic perception difference in dealing with international conflicts? To the meaning of foreign culture, education and information policy in Germany and USA. Politische Vierteljahresschrift50, 672-674 (2009).

[10] Gelfand, MJ Culture's Constraints:. International Differences in the Strength of Social Norms Current Directions in Psychological Science21, 420-424 (2012).

[11] Pothukuchi, V., Damanpour, F., Choi, J., Chen, CC \& Park, SH National and organizational culture differences and international joint venture performance. Journal of International Business Studies33, 243-265 (2002). 
[12] Pasque, PA, Chesler, MA, Charbeneau, J. \& Carlson, C. Pedagogical Approaches to Student Racial Conflict in the Classroom. Journal of Diversity in Higher Education6, 1-16 (2013).

[13] Alford, J. \& Jetnikoff, A. High-challenge Teaching for Senior English as an Additional Language Learners in Times of Change. English in Australia46, 11-20 (2011).

[14] Glasgow, J. \& Skinner, B. Teaching Children English as an Additional Language: Meeting the Challenge in the Classroom Elt Journal63, 425-U139 (2009).

[15] Garn, AC, Ware, DR \& Solmon, MA Student Engagement in High School Physical Education:? Do Social Motivation Orientations Matter Journal of Teaching in Physical Education30, 84-96 (2011).

[16] Bozalek, V. et al The use of emerging technologies for authentic learning:.. A South African study in higher education British Journal of Educational Technology44, 629-638 (2013).

[17] Fahad, A., Hassan, Z. \& Salman, Z. A Study Towards Using Elearning Based Information Technology Resources for the Development of Students Thinking Skills in Higher Education, in Fourth International Conference on Intelligent Systems, Modelling and Simulation. (eds. D. AlDabass, P. Uthayopas, S. Sanguanpong \& J. Niramitranon) 331-3342013).

[18] Ng'ambi, D., Bozalek, V. \& Gachago, D. Empowering Educators to Teach Using Emerging Technologies in Higher Education: A Case of Facilitating a Course Across Institutional Boundaries, in Proceedings of the 8th International Conference on E-Learning . (ed. E. Ivala) 292-3002013).

[19] Pagano, R. \& Paucar-Caceres, A. Using systems thinking to evaluate formative feedback in UK higher education: the case of classroom response technology Innovations in Education and Teaching International50, 94-103 (2013)..
[20] Teaching Strategies \& Yang Lu Ming CLIMATE CONDITIONS active learning. Education and Modernization, 21-27 (2007).

[21] Liu shibin. Bloom Taxonomy of Educational Objectives from the perspective of effective teaching. Teaching Research for Primary, 3-5 (2013).

[22] He Chunlin leading Web-App trend of multimedia files nested - A Case Study in Moodle China - ASEAN Expo, 199-200 (2013).

[23] Li Guangjie Moodle-based build an open network teaching platform. The development and application of computer, 9-11 (2013).

[24] Li Wei Moodle learning platform Reviews and middle school audiovisual (below), 61 (2013).

[25] Qi Wanli, Zhou Ming \& a loving Moodle-based collaborative learning model Effectiveness - A Case Study in College English Teaching fiction reviews, 362-366 (2013).

[26] Beam Aerospace Research based IT platform Moodle Learning. Primary and secondary audio-visual (below), 17 (2013).

[27] Construction and Application of Moodle environment under 27. Chun term vocational colleges boutique class resource sharing platform Jiamusi Education Institute, 247 + 263 (2013)

[28] Zhang Jin coup made their victory - on "Moodle Forum Module" audio-visual exploitation of primary and secondary schools (under), 14-15 (2013)

[29] Zhang Moodle NanoGong often heard in College English Teaching Online electronic production, 172 (2013).

[30] Zhangya Qiong \& Conde Star on Easy classes (E-CLASS) positioned in a learning class construction. China Education Innovation Herald, 207 (2011). 